\title{
MELILLA Y LA LEY DE EXTRANJERÍA DE 1985. TRASCENDENCIA INTERNACIONAL DE UN CONFLICTO LOCAL. ANÁLISIS DE TRES PERIÓDICOS
}

\author{
MELILLA AND THE 1985 IMMIGRATION LAW. \\ INTERNATIONAL TRASCENDENCE OF A LOCAL CONFLICT. \\ A REVIEW OF THREE NEWSPAPERS
}

\author{
Sonia RUBIANO SEGOVIA* \\ USBAD Teniente Flomesta
}

\section{Resumen}

La ley de Extranjería de 1985 no había tenido en cuenta a las miles de personas que habían nacido o vivían en Melilla desde hacía varias generaciones, pero que no tenían ningún derecho como ciudadanos. Bajo el liderazgo de Aomar Mohamedi Duddú, el colectivo musulmán de Melilla se movilizó para reclamar su derecho a obtener la nacionalidad española. El objetivo de este artículo es analizar la imbricación de este conflicto, que se desarrolló entre 1985 y 1987, y que era a priori local, con las reclamaciones territoriales de Marruecos, y la dimensión internacional que alcanzó, a través del análisis de lo que al respecto publicaron tres periódicos de tirada nacional: $A B C$, El País y La Vanguardia a lo largo de esos años.

Palabras clave: Melilla, ley de Extranjería, Duddú, Marruecos, Prensa.

\begin{abstract}
The 1985 Immigration Law had not taken into account thousands of people who had been born or had been living in Melilla for generations, but who had no rights as citizens. Under the leadership of Aomar Mohamedi Duddu, the Muslim colective in Melilla mobilised to claim their right to obtain the Spanish nationality. The objective of this paper is to analyse the interweaving of this conflict, which developed between 1985 and 1987, and that was a priori local, with the Moroccan territorial claims, and the international dimension it reached, through the analysis of what three main newspapers, $A B C$, El País and La Vanguardia, published about this issue along those years.
\end{abstract}

\footnotetext{
* Investigadora en formación en el Programa de doctorado en Seguridad Internacional de la Universidad Nacional de Educación a Distancia (UNED) srubiano1@alumno.uned.es
} 
Key words: Melilla, Immigration Law, Duddu, Morocco, Press.

\section{INTRODUCCIÓN}

La hipótesis de trabajo de la que se parte quiere analizar cómo un hecho acontecido en un periodo de tiempo breve, entre 1985 y 1987, en un escenario exiguo (Melilla mide doce kilómetros cuadrados), puede reflejar la trascendencia que cualquier acontecimiento en la ciudad norteafricana tiene en las relaciones hispano-marroquíes. $\mathrm{La}$ situación de conflicto que se dio en ese momento concreto y las implicaciones internacionales que tuvo constituyen un claro ejemplo de lo que plantea la hipótesis inicial.

El cuerpo fundamental de este artículo es el análisis de lo publicado sobre Melilla y la ley de Extranjería de 1985 en prensa escrita, así como aquellos artículos relacionados con las reacciones de Marruecos ante la evolución de los acontecimientos en la ciudad (en Ceuta el conflicto no adquirió la gravedad que sí tuvo en Melilla). Para la confección de este trabajo se ha recurrido a las hemerotecas de tres periódicos de tirada nacional: $E l$ País, ABC y La Vanguardia. En esos años eran los de mayor difusión, lo que, según Szmolka, es el principal criterio de inclusión (Szmolka, 2005, 27). Se han revisado casi 1300 artículos: 440 de $A B C, 490$ de El País y 360 de La Vanguardia, correspondientes al periodo comprendido desde el 8 de enero de 1985 hasta el 28 de diciembre de 1987, ya que toda la atención informativa se concentró en esta franja temporal.

\section{LA LEY DE EXTRANJERÍA DE 1985 Y MELILLA}

Es necesario hacer un breve resumen de la manera en que se desarrolló el conflicto en Melilla a raíz de la aplicación de la ley de Extranjería en la ciudad, para así poder contextualizar la trascendencia internacional que adquirió. Por Derecho de Extranjería del Estado español se entiende el conjunto de normas jurídicas que en dicho espacio regulan la relación que se establece entre el extranjero y el Estado por la mera presencia física de aquel en el territorio sometido a la jurisdicción de este (Oraa, Ruiz y Gil, 1997, 314). El Gobierno de Unión del Centro Democrático (UCD) intentó en 1981 adecuar la legislación sobre extranjería a las disposiciones constitucionales, pero fracasó por la disolución de las Cámaras en 1982. En enero de 1985, el Gobierno del Partido Socialista Obrero Español (PSOE) presentó un nuevo proyecto de ley, tramitado por el procedimiento de urgencia ${ }^{1}$, que obtuvo un amplio consenso de los grupos parlamentarios

\footnotetext{
${ }^{1}$ Los motivos de la urgencia de esta ley pueden encontrarse en Sainz de la Peña, 1997, 128.
} 
y que fue aprobado por 260 votos a favor y solo tres en contra. Era la ley Orgánica 7/1985, de 1 de julio, sobre Derechos y Libertades de los Extranjeros en España ${ }^{2}$.

Iberoamericanos, portugueses, filipinos, andorranos, ecuatorianos, sefardíes y los originarios de Gibraltar podrían beneficiarse de un trato preferencial para acceder a la nacionalidad española. La ley de Extranjería, sin embargo, no preveía ese mismo trato para aquellos habitantes de Ceuta y Melilla que no dispusieran de documentación española y que por tanto podían ser expulsados al encontrarse en una situación irregular (Planet, 1998, 164). En el momento de publicarse la ley de Extranjería, la mayoría de la población musulmana residente en Ceuta y Melilla (83,6\% y 82,5\% respectivamente), pese a haber nacido en las ciudades y vivir en ellas desde hacía tiempo, no tenía nacionalidad española (Planet, 1988, 85). Una parte importante de este colectivo poseía una tarjeta de estadística, de validez restringida a las ciudades norteafricanas. Rebautizada por los musulmanes como chapa de perro (Flores, 1995, 10), no otorgaba ningún tipo de derechos reales a sus titulares, más que una situación arbitraria de consentimiento de la residencia por parte de la autoridad, carente de las mínimas garantías sociales (Belmonte, 2010, 85).

En octubre de 1985 el Gobierno español señalaba a los musulmanes de Melilla y Ceuta como extranjeros en su propia ciudad y, si nada cambiaba, estos se verían forzados a la expulsión al otro lado de la frontera. Meses antes había sido creada en Melilla la asociación socio-cultural Terra Omnium, a la cabeza de la cual estaba el economista melillense Aomar Mohamedi Duddú, militante del PSOE. Este publicó el 11 de mayo de 1985 Legalizar Melilla (Duddú, 1985) en El País, un artículo en el que criticaba las tesis oficiales sobre la ciudad de Melilla, aunque fue escrito por el entonces delegado de Cultura en la ciudad, Jesús Morata, como él mismo reconoció (https://jesusmoratavideos-y-postales/entrevista-a-jesus-morata/). Según él, existía un censo irreal que desdeñaba a los musulmanes radicados en la ciudad que carecían de documentación española y además, la integración de los musulmanes en la sociedad melillense no era más que una tolerancia sin convivencia. Duddú proponía la concesión del Documento Nacional de Identidad a todo musulmán que lo solicitase y demostrase haber nacido en Melilla. Tras la publicación de este artículo, la reacción de los partidos políticos con implantación en la ciudad fue de rechazo unánime de su contenido y el PSOE lo suspendió de militancia (Planet, 1998, 89).

El 23 de noviembre, por primera vez desde la independencia de Marruecos, una manifestación del colectivo musulmán atravesaba Melilla. Miles de personas se

${ }^{2}$ Ley Orgánica 7/1985, de 1 de julio, sobre derechos y libertades de los extranjeros en España. BOE núm. 158, de 3 de julio de 1985, pp. 20824-20829. 
agruparon tras una pancarta que decía: No a la ley de Extranjería. Somos Melillen$\operatorname{ses}^{3}$. En respuesta a esta manifestación, el 6 de diciembre se convocó otra por todos los partidos locales, bajo el lema: Por la Constitución y por los Derechos Humanos, sí a la ley de Extranjería. El número de manifestantes desbordó las previsiones más optimistas: acudieron entre 30.000 y 40.000 personas (Belmonte, 2010, 46).

El 16 de diciembre se trasladaba a Madrid una comisión conjunta de musulmanes melillenses y ceutíes, encabezada por Duddú y Ahmed Subaire, el líder de los musulmanes en Ceuta, con un objetivo: conseguir una moratoria en la aplicación de la ley de Extranjería en las dos ciudades, más allá del 31 de enero de 1986, a fin de negociar con tiempo suficiente una salida al conflicto. Como contrapartida, los musulmanes cesarían en sus movilizaciones mientras se mantuviera dicha moratoria. El 10 de febrero se produjo el triple apretón de manos entre Rafael Vera, subsecretario del Ministerio del Interior, Duddú y Subaire, que cerraba el Acuerdo entre Administración y musulmanes, gracias al cual los representantes de la población melillense y ceutí de origen marroquí se sentarían junto a los del Gobierno en una Comisión Mixta cuyo objeto declarado era favorecer la plena integración de los residentes musulmanes en el territorio nacional.

A mediados de mayo el tono del descontento magrebí subió. Tras tres meses desde la firma de los acuerdos con el Gobierno, la comunidad musulmana no había obtenido respuesta positiva a ninguna de las más de cuatro mil peticiones de nacionalidad cumplimentadas durante ese periodo (Belmonte, 2010, 120). En Madrid se buscaron entonces nuevas formas de diálogo. Duddú fue nombrado asesor para minorías étnicas en el Ministerio del Interior, lo que en principio no fue bien recibido por sus seguidores, ya que su marcha a Madrid podría comprometer la lucha iniciada en Melilla. Finalmente, aceptó el cargo, pero duró poco tiempo en él. El 8 de noviembre convocó una asamblea donde, además de comunicar que abandonaba su puesto en Madrid, se leyó un comunicado en el que, entre otras cosas, se reclamaba el derecho al carácter árabe y musulmán de la ciudad, la solicitud de la doble nacionalidad española y marroquí para los melillenses y se reivindicaba una Melilla árabe y musulmana (Ramírez, 1986, 9 de noviembre).

El año 1987 se inició con manifestaciones y cierres de comercios, pero la dimensión aún aparentemente local del conflicto se amplió. A las declaraciones pro-marroquíes de Duddú siguieron las amenazas de expulsión esgrimidas por el Delegado del Gobierno de los indocumentados que apoyaran esas tesis. El 31 de enero hubo nuevos

\footnotetext{
${ }^{3}$ Según los organizadores, fueron 22.000 personas; según la policía, 7.000 (Carabaza, E.; De Santos,
} M.,1992, 112). 
choques entre musulmanes, fuerzas del orden y civiles armados. Veintiséis de los detenidos en los incidentes fueron acusados de sedición y nueve de ellos trasladados a la prisión almeriense de El Acebuche. Duddú había cruzado la frontera la noche del 30 para refugiarse en Marruecos. El 3 de febrero fue procesado por un delito de sedición, como incitador de un movimiento de subversión. En los primeros días de julio fue nombrado un juez específico para gestionar la concesión de nacionalidades a los musulmanes indocumentados en Melilla que reunieran los requisitos de haber nacido en la ciudad y tener un arraigo demostrable. Este proceso extraordinario de concesión de nacionalidades (más de 5000 en Melilla y 1000 pendientes de tramitación en los juzgados ordinarios) se dio por concluido en diciembre de 1988.

\section{DE LO LOCAL A LO INTERNACIONAL}

Conviene destacar el interés que mostraron los tres periódicos estudiados por la aplicación de la ley de Extranjería en Ceuta y Melilla. De ambas ciudades se habló además en múltiples ocasiones en foros internacionales durante el periodo de tiempo analizado. Se han seleccionado momentos puntuales, y se han agrupado bajo distintos epígrafes los actores más significativos para entender la importancia que la prensa le dio al conflicto en Melilla y Ceuta, y la dimensión internacional que este alcanzó.

\subsection{DUDDÚ: EMERGENCIA Y CAÍDA}

El texto fundacional del movimiento reivindicativo de la comunidad musulmana en Melilla es el artículo que se publicó bajo la firma de Aomar Mohamedi Duddú en El País, titulado Legalizar Melilla (Duddú, 1985, 11 de mayo). En él, además de desmontar la visión edulcorada que se tenía de la convivencia entre cristianos y musulmanes, ya se insinuaba la amenaza de una progresiva ocupación de marroquíes debido a la presión demográfica:

En líneas generales... Melilla es una bella ciudad española ... amenazada sólo por los esporádicos rigores del control aduanero y, sobre todo, por la llamada Marcha de la Tortuga (concepto que, en contraposición a la veloz Marcha Verde sahariana, alude a la lenta y continua invasión de Melilla por parte de musulmanes de origen marroquí, que, faltos de documentación, van desequilibrando a su favor la correlación demográfica de la ciudad).

También denunciaba las pésimas condiciones de vida de la población musulmana, de la que decía que en su mayor parte carecía de cualquier documentación marroquí, y reclamaba la nacionalidad española para todos ellos. Además, afirmaba 
que en el trato a los musulmanes de Melilla había comportamientos similares a los de la República Surafricana y al Chile de Pinochet: segregación racial, dictadura y violación de derechos humanos:

Para quienes defienden la concepción tradicional de Melilla, los musulmanes deben quedarse a vivir en ella (los necesitan como clientes y subempleados), pero nunca en igualdad de derechos (para ello se les niega la nacionalidad española). Las argumentaciones para justificar este despropósito son abundantes e incluyen, en proporción variable, el ultraespañolismo, el paternalismo, el orden público y el racismo puro y simple.

En marzo de 1986, el diario $A B C$ afirmaba que muchos musulmanes de Ceuta y Melilla no tenían intención de adquirir la nacionalidad española, bien por miedo a represalias por parte marroquí, o por sus vínculos familiares, sociales y laborales con Marruecos, o porque la nacionalización supondría el fin de su forma de vida y cultura. Este hecho supondría un duro golpe a la credibilidad de los líderes musulmanes de ambas ciudades, Duddú y Subaire ( $A B C, 1986,28$ de marzo). Aunque la legislación española no reconoce la posibilidad de que una misma persona posea al mismo tiempo la nacionalidad española y la marroquí porque no existe un convenio entre ambos países en esta materia, esto no es así para el Derecho marroquí, que prescribe quiénes son sus nacionales sin tener en cuenta las singularidades del Derecho español, y establece que tienen nacionalidad marroquí las personas nacidas de padre marroquí o de madre marroquí y padre desconocido, con lo cual la nacionalidad se transmite de padres a hijos (Loureiro, 2015, 488).

Meses más tarde, de nuevo $A B C$ fue más allá al insinuar que Aomar Mohamedi Duddú, el nuevo asesor del ministro Barrionuevo y líder musulmán melillense, podría haber mantenido contactos secretos con el Gobierno de Marruecos (Carrascosa, 1986, 9 de octubre). Este comentario reflejaba con acierto la situación paradójica en la que se desarrollaba el conflicto, y para el que nadie parecía encontrar solución:

Un líder político que ha hecho carrera en Melilla apoyándose en las reivindicaciones de un colectivo de musulmanes que aspiran a ser tratados como españoles de pleno derecho (muy lejos de sus deseos la nacionalidad marroqui) percibe un sueldo del Gobierno de Madrid, pero al mismo tiempo parece que trabajase por libre para el Gobierno de Rabat... Duddú es capaz de expresar por encima de todos los desprecios y acabar por efectuar, y él mismo lo promueve, planteamientos tragicómicos que reducen la cuestión a una disparatada guerra de "moros" contra "cristianos".

En noviembre Duddú anunciaba su dimisión como asesor de minorías étnicas del Ministerio del Interior, en una asamblea en la que participaron unos dos mil asistentes, y en la cual rompía su relación con la Comisión Mixta. Otro asistente, Abdelkader 
Mohamed Moh, hizo una propuesta de declaración institucional en la que abogaba por la doble nacionalidad para los ciudadanos de Melilla. Acababa así: Melilla, mogrebí, árabe y musulmana, contará con el apoyo de los pueblos árabes, afines y de las instituciones democráticas, especialmente las situadas en el reino de Marruecos (Ramírez, 1986, 9 de noviembre). A principios de febrero del año siguiente, Duddú era procesado por un delito de sedición como incitador de un movimiento de subversión, y el juez José María Treviño ordenó su ingreso en prisión (Grijelmo, 1987, 5 de febrero). Finalmente se acercó al Rey Hassán II y acabó exiliándose en Rabat. Allí iba a dedicarse a redactar para las autoridades marroquíes un detallado informe sobre la situación social, política y económica de Melilla (La Vanguardia, 1987, 7 de mayo).

Antes de eso, estuvo un tiempo viviendo en la ciudad marroquí de Nador, próxima a Melilla, desde donde dio varias ruedas de prensa, a las que acudieron en alguna ocasión, además de periodistas de medios españoles, reporteros de la $B B C$ inglesa ( $L a$ Vanguardia, 1987, 5 de febrero). El Gobierno español advirtió al marroquí que consideraría una grave ofensa la concesión a Duddú de un estatuto de refugiado político ( $\mathrm{La}$ Vanguardia, 1987, 2 de febrero). Aprovechando la dinámica creada en Melilla con Duddú, se dio un cambio en la doctrina oficial de Marruecos sobre el contencioso de Ceuta y Melilla. Así, si hasta ese momento Marruecos había intentado encontrar un paralelismo con Gibraltar, y había recurrido a justificaciones geoestratégicas para rechazar que la colonia inglesa y las dos ciudades norteafricanas fueran del mismo país, con la presencia de Duddú todo había cambiado, ya que en Gibraltar no había una figura similar a la del líder melillense, y no había grupos pro-españoles, como sí habían aparecido grupos pro-marroquíes en Melilla (Miguez, 1987, 7 de febrero).

\subsection{HASSÁN II}

Entre los resortes utilizados por la Monarquía marroquí para consolidar su hegemonía en el campo político se encontraría, según algunos autores, su control sobre la política exterior, ya que esta se integra dentro de lo que se conoce como los dominios reservados al Monarca, junto con la defensa y la seguridad nacionales, en base a una tradición precolonial de la que el Estado marroquí contemporáneo se reclama continuador (Fernández, 2013, 63). El Rey, situado en la cúspide de la jerarquía gubernamental, define globalmente la política exterior marroquí. Los miembros del Gobierno y los funcionarios técnicos de los diferentes ministerios son los encargados de definir los medios para alcanzar los objetivos fijados por el Soberano, pero no tienen la posibilidad de juzgar ni la oportunidad ni el alcance de la decisión adoptada (Hernando de Larramendi, 1995, 58-62). 
El diplomático español Ángel Ballesteros defiende que Marruecos no aprovechó especialmente la aplicación de la ley de Extranjería para reivindicar Ceuta y Melilla a partir de 1986 por diversos motivos: el Gobierno español del PSOE se estaba alejando paulatinamente de las posturas en favor del Frente Polisario en el conflicto del Sáhara, sobre todo tras el ataque al pesquero Junquito y a la patrullera Tagomago el 20 de septiembre de 1985. Además, en diciembre de 1985 España había concedido nuevos créditos de Fondo de Ayuda al Desarrollo (FAD) a Marruecos. El 1 de enero de 1986 España ingresaba en la Comunidad Económica Europea (CEE), lo que la situó como la puerta de entrada (o barrera) de los productos marroquíes a Europa. El factor económico pesaba (Ballesteros, 1998, 268). No obstante, la prensa española en este periodo se encargó de anunciar cada una de las veces en las que el Rey Hassán II, o su Gobierno, a través de los distintos ministros, o incluso partidos políticos en la oposición, reclamaron la soberanía de Ceuta y Melilla para el reino alauí.

En 1985, el Rey Hassán II apenas habló en la prensa de Melilla y Ceuta. Recién comenzado el año, concedió una entrevista a un diario árabe, Ach Charq el Aussat, financiado por instituciones saudíes y que se publicaba en Marruecos, en la que afirmaba que la solución al problema de las dos ciudades solo podía ser política, y renunciaba expresamente a hacer uso de la fuerza, a menos que España tomase una iniciativa militar (Del Pino, 1985, 10 de enero). A finales de año ordenó a su Gobierno que negociara con el español el estatuto de los ciudadanos marroquíes que residían tanto en Ceuta y Melilla como en la Península ( $A B C, 1985,7$ de diciembre). El Gobierno español, por la vía diplomática, tranquilizó al Rey de Marruecos asegurándole que la aplicación de la nueva ley de Extranjería no daría como consecuencia expulsiones masivas de marroquíes desde los puestos fronterizos de Ceuta y Melilla (Orgambides, 1985, 7 de diciembre).

Si hubo una constante en las reivindicaciones territoriales del monarca alauí, esta fue el vincularlas al destino de la colonia británica de Gibraltar. En ocasiones Hassán II declaraba que Ceuta y Melilla pasarían a ser marroquíes en cuanto Gibraltar volviera a ser de soberanía española, y había momentos en los que explícitamente independizaba las circunstancias de la colonia inglesa y de las ciudades españolas. El 3 de marzo de 1986, el Rey Juan Carlos I viajaba a Marruecos con motivo del $25^{\circ}$ aniversario de la llegada al trono del Rey Hassán II. Cinco días después, el monarca alauí reconoció haber hablado con su homólogo español sobre Ceuta y Melilla, y se lamentaba de la situación de sus compatriotas en Melilla, sobre todo después de que un grupo de mujeres musulmanas hubiera sufrido una carga policial tras manifestarse en contra de la ley de Extranjería, a finales de enero (Ramírez, 1986, 29 de enero). También aseguró 
que los casos de Ceuta y Melilla no eran paralelos al de Gibraltar (Miguez, 1986, 8 de marzo). En esta ocasión, desvinculó los contenciosos de Gibraltar y de Ceuta y Melilla.

Entre 1975 y 1986 había sucedido lo contrario. En octubre de 1975 el representante permanente de Marruecos en la ONU, Driss Slaoui, dirigió una carta al Comité de los 24, o Comité Especial para la Descolonización, en la que pedía que Ceuta, Melilla y las islas y peñones de soberanía española fueran incluidos en la lista de Territorios no Autónomos, para que el Comité analizara su situación colonial, idéntica, según el diplomático marroquí, a la de Gibraltar desde los puntos de vista histórico, jurídico y político. Según los marroquíes, en el caso de que Gibraltar pasase a manos españolas, las grandes potencias no permitirían que un mismo Estado controlase las dos orillas del Estrecho (Lemus, 2005, 123-124).

En los últimos días de marzo de 1986 el Rey marroquí afirmó que, de producirse una nueva Marcha Verde sobre ambas ciudades, esta sería la de la paciencia, la determinación, el diálogo, la ponderación y la persuasión, cinco puntos que definían el mensaje político que en ese momento la corona marroquí quería dar sobre el contencioso de Ceuta y Melilla ( $A B C, 1986,26$ de marzo). Además, desautorizaba las voces del Istiqlal, que en los meses previos había protagonizado una campaña histérica, como la definía El País, en la que hablaba de marchas verdes, movilizaciones populares, e incluso de guerra para liberar las dos ciudades. De nuevo insistía en estas declaraciones en vincular el futuro de Gibraltar con el de Ceuta y Melilla, ya que entendía que los soviéticos jamás permitirían que un único país miembro de la OTAN controlara las dos orillas del Estrecho (El País, 1986, 26 de marzo).

A principios de 1987, Hassán II lanzaba una invitación al Gobierno español: la creación de un grupo o célula de reflexión sobre Ceuta y Melilla. El ministro de Asuntos Exteriores, Fernández Ordóñez, negó que el ministro del Interior, Barrionuevo, hubiera llevado un mensaje escrito del Rey de Marruecos al de España (El País, 1987, 23 de enero). La Prensa marroquí criticó airadamente el rechazo español a la propuesta del monarca magrebí de constituir una Comisión hispano-marroquí que estudiara el proceso de descolonización de Ceuta y Melilla ( $A B C, 1987,24$ de enero). Unos meses más tarde, el Rey alauí señaló las diferencias entre Gibraltar y las dos ciudades españolas del norte de África: para él, Ceuta y Melilla eran elementos coloniales, y se encontraban en territorio marroquí, y Gibraltar se encontraba en Europa y formaba parte de una potencia europea, aliada de España en la OTAN y el Mercado Común ( $A B C$, 1987, 13 de abril). Sin embargo, en julio Hassán II volvía a unir el futuro de Gibraltar a Ceuta y Melilla, de manera que, si los ingleses cedían Gibraltar, Marruecos recuperaría rápidamente Ceuta y Melilla $(A B C, 1987,13$ de julio). 
Hay que tener en cuenta que, por una parte, desde hacía dos años, se estaban gestando los estatutos de Autonomía de ambas ciudades, con lo que se conseguiría su plena integración dentro del mapa autonómico español, y dejarían de encontrarse en el limbo territorial en el que hasta ese momento se hallaban, con lo que las reivindicaciones marroquíes perderían mucha fuerza, al menos en lo que respecta a España. Además, no hay que olvidar que lo que reclamaba la comunidad musulmana de Melilla (y de Ceuta) era poder acceder a la nacionalidad española, mientras que Hassan II buscaba la retrocesión de ambas ciudades y que pasaran a ser marroquíes.

\subsection{GOBIERNO Y PARTIDOS POLÍTICOS MARROQUÍES}

Lo reducido de las atribuciones constitucionales del Gobierno marroquí y su dependencia directa del Rey le permiten muy poca autonomía en el diseño de la política exterior y reducen sus funciones al terreno administrativo (Fernández, 2013, 61). En virtud de la legislación vigente, la administración central tiene la amplitud de autorizar o negar la creación de un partido político teniendo en cuenta la postura que éste adopte respecto al sistema monárquico (Boundi, 2010, 2). Según algunos autores, Marruecos nunca vio estas reivindicaciones de las poblaciones musulmanas de Ceuta y Melilla como un contratiempo, sino como una oportunidad para ejercer más presión sobre las dos ciudades. Otros, por el contrario, opinan que Marruecos veía con disgusto que las reivindicaciones de los musulmanes de ambas ciudades se concretaran en la exigencia de la adquisición de la nacionalidad española (Lemus, 2005, 544).

En noviembre de 1985 el presidente de la Asamblea de Diputados de Marruecos y ex primer ministro, Ahmed Osman, afirmó que la nueva ley de Extranjería podría plantear graves dificultades entre España y Marruecos a causa de la situación intolerable en que vivían los ciudadanos marroquíes de Ceuta y Melilla ${ }^{4}$. Osman insistió en el problema de los ciudadanos marroquíes que se encontraban en ambas ciudades, obviando el hecho de que este colectivo no reivindicaba precisamente su marroquinidad sino lo contrario, el derecho que les asistía a ser españoles (Miguez, 1986, 26 de noviembre). En esa aparente contradicción se movieron no solo los miembros del Gobierno marroquí, sino también el resto de partidos políticos, sobre todo el nacionalista y conservador Istiqlal: los musulmanes residentes en Melilla querían ser sobre todo españoles, aunque tampoco quisieran renunciar a la nacionalidad marroquí.

\footnotetext{
${ }^{4}$ Como señala Szmolka, la diplomacia mediática, es decir, el intercambio de mensajes entre España y Marruecos a través de la prensa, siempre ha sido muy fluida (Szmolka, 2005, 35).
} 
A principios de diciembre el Istiqlal declaró que la situación de la población marroquí residente en Melilla era preocupante a causa de la ley de Extranjería, y que la ley quería desembarazarse de esta población, que continuaba manifestando el carácter marroquí de las dos ciudades (La Vanguardia,1985, 4 de diciembre). Además, los nacionalistas marroquíes iban a movilizar a sus militantes para liberar el norte de $\mathrm{Ma}$ rruecos como lo hizo para recuperar el Sáhara, a la vez que daban datos de una mayor difusión internacional del conflicto, mientras calificaban de inhumana e ilegal la situación de los musulmanes de Ceuta y Melilla. Radio Trípoli, y un periódico de Argel y otro de Túnez se habían sumado a la campaña contra la ley de Extranjería, junto con las protestas diarias de la prensa marroquí (Orgambides, 1985, 10 de diciembre).

La postura del Istiqlal en el conflicto ocasionado por la aplicación de la ley de Extranjería en Melilla le resultó en ocasiones incómoda al rey de Marruecos. Así como lo reducido de las atribuciones constitucionales del Gobierno y su dependencia directa del monarca le permitían una autonomía muy reducida en el diseño de la política exterior y reducían sus funciones al terreno administrativo (Fernández, 2013, 61), las funciones de los partidos políticos que no estaban en el Gobierno oscilaban entre la cooperación, el apoyo crítico y la contestación (Fernández, 2013, 62).

A principios de 1986, el presidente del Istiqlal, Abdelhaq Tazi, pedía la liberación de Ceuta y Melilla (La Vanguardia, 1986, 18 de enero), y se emprendió una campaña de la prensa marroquí contra las dos ciudades. El periódico L' Opinion, publicado por el Istiqlal, (Park; Boum, 2005, 243) informaba del bloqueo de las cuentas corrientes de aquellos que no regularizaran su situación antes del 31 de enero. Después se dirigía al Gobierno marroquí y le preguntaba sobre las medidas que iba a adoptar para defender los intereses y los derechos de los marroquíes de Ceuta y Melilla. El Alam (La Bandera), de ideología conservadora y socialdemócrata (Jedidi, 2019), destacaba que la ley de Autonomía para Ceuta y Melilla reforzaría la presencia económica, social y militar española, lo que haría perder la especificidad marroquí de las dos ciudades. Al Bayan, de ideología socialista y muy crítico con el Gobierno, fundado por el Partido Socialista y del Progreso en 1971 (Park; Boum, 2005, 243), señalaba que muchos marroquíes estaban sacando su dinero de los bancos de Ceuta y Melilla ( $A B C, 1986,26$ de enero).

El Istiqlal convocó para el 14 de febrero una concentración en la localidad marroquí de Nador, vecina a Melilla, para solidarizarse con la colonia musulmana de esta ciudad y condenar la represión española. Se esperaba la intervención de Mohamed Bucceta, máximo dirigente del partido y antiguo ministro de Asuntos Exteriores $(A B C, 1986,7$ de febrero). En el tema de Ceuta y Melilla, los partidos políticos marroquíes, en especial los 
nacionalistas, tenían una válvula de escape doble: daban salida a su profundo sentimiento nacionalista, lo que siempre movilizaba a las masas, y servía como medio para presionar a Hassán II, ya que por otros medios era imposible (Lemus, 2005,125).

Meses más tarde, Abderrahim Buabid, ex ministro y dirigente de la oposición socialista marroquí, señalaba que había que establecer un diálogo con España de la misma manera que la República Popular China estaba haciendo con el Reino Unido sobre Hong Kong (que acabaría con la transferencia de su soberanía en 1997), y destacaba que, como en Hong Kong había industrias y exportaciones, los chinos no habían pedido su devolución inmediata, porque les procuraba divisas. En cambio, Ceuta y Melilla tenían un pasado anacrónico sostenido por españoles, en su mayoría militares, policías y traficantes (Orgambides, 1986, 23 de octubre). En Rabat se recibían con satisfacción los últimos acontecimientos en Melilla, en especial la declaración del carácter árabe, musulmán y magrebí de la ciudad. Istiqlal y socialistas marroquíes habían hecho una interpretación diferente de estas palabras: los nacionalistas insistían en que todos los territorios españoles del norte de África no son sólo magrebíes, sino marroquíes. Los socialistas decían que los musulmanes de Melilla habían pedido la doble nacionalidad (Orgambides, 1986, 11 de noviembre).

En diciembre, el Gobierno marroquí decidió informar sobre Ceuta y Melilla a los ministros y responsables de Estados de la Comunidad Europea que visitaran Marruecos como un intento desde el poder de calmar las exigencias de la oposición, especialmente a socialistas y al Istiqlal, que pedían no sólo un posicionamiento público de Rabat, sino que se aireara internacionalmente el conflicto. En esos días visitaban Rabat diplomáticos y políticos belgas, daneses y portugueses, y se esperaba la llegada de dos secretarios de Estado españoles, el de Cooperación Internacional, Luis Yáñez, y el de Relaciones con la CEE, Pedro Solbes (Orgambides, 1986, 1 de diciembre). Además, el ministro de Información y de Turismo, Mulay Ahmed Alaoui, aseguraba a Le Matin du Sahara, el periódico oficial del Gobierno marroquí publicado en francés (Park; Boum, 2005, 243), que la situación de Ceuta y Melilla preocupaba a todos los marroquíes, por la presencia española en las ciudades (marroquíes, según el periódico) y por la lucha que venían manteniendo sus habitantes contra esa presencia española (Orgambides, 1986, 3 de diciembre).

El 10 de febrero de 1987 el Partido Socialista Marroquí anunciaba su intención de llevar el contencioso de Ceuta y Melilla ante el Parlamento y Tribunal Europeos de Estrasburgo, según había declarado el día anterior su secretario general, Buabid. Él sí recurrió al paralelismo con Gibraltar, cuando la doctrina oficial marroquí en ese momento era la contraria, en el sentido de que lo que España buscaba era nacionalizar al 
máximo número de habitantes para, a continuación, celebrar un referéndum sobre la continuidad de la pertenencia a España o no (La Vanguardia, 1987, 10 de febrero).

Marruecos presentó su petición oficial de adhesión a la CEE el 20 de julio. El ministro de Asuntos Exteriores marroquí, Abdelatif Filali, preguntado sobre esta adhesión y Melilla y Ceuta, respondió que ese era un tema bilateral que no debía plantearse en la CEE (Garrigo, 1987, 21 de julio). A pesar de que Marruecos disfrutaba de un régimen de acceso preferencial al Mercado Común para la mayor parte de los productos del Estado magrebí desde 1969, seguido por un Acuerdo de Asociación y uno de Cooperación de 1976, el alcance de las ventajas comerciales fue menguando conforme avanzaba la integración europea, pues la proteccionista Política Agraria Común transformó a la CEE en autosuficiente y exportadora. La incorporación de Grecia, España y Portugal conllevó una reducción de las cuotas asignadas a Marruecos. La percepción marroquí de agravio y exclusión progresiva podría explicar esta solicitud de adhesión, que fue rechazada de plano en octubre, aunque Marruecos obtuvo algunas concesiones comerciales, como un acuerdo de pesca con la CEE que hasta entonces era solo bilateral con España (De la Fuente, 1989, 76-77).

\subsection{GOBIERNO ESPAÑOL}

Cuando el PSOE llegó al Gobierno, no cuestionó las grandes orientaciones de la política exterior española sino que, por el contrario, puso en pie una política pragmática y desideologizada, de abandono del radicalismo en favor de un cierto posibilismo (Lemus, 2005, 152). La estrategia global pretendía fomentar buenas relaciones bilaterales simultáneas con todos los Estados del Magreb, de modo que no fuera necesario realizar una política de gestos dirigidos alternativamente hacia Marruecos y Argelia (Lemus, 2005, 261-262). Las tesis defendidas por el PSOE desde la oposición en la cuestión del Sáhara fueron sacrificadas en aras de una política de Estado continuista. Así, el Gobierno de Felipe González renunció a reconocer diplomáticamente a la República Árabe Saharaui Democrática, aunque las relaciones de partido entre los socialistas españoles y el Frente Polisario fueron mantenidas, incluso en los momentos de tensión, como en septiembre de 1985, tras el ametrallamiento del pesquero Junquito y de la patrullera Tagomago (Thieux, 2007, 245).

La voluntad del Gobierno socialista de normalizar las relaciones encontró el eco adecuado en Marruecos. Rabat redujo la intensidad de sus presiones sobre España, contentándose con que Madrid no obstaculizase eventuales salidas pacíficas a la cuestión del Sáhara Occidental (Hernando de Larramendi, 1997, 405). Hay que destacar 
que, entre 1975 y 1994, solo hubo dos años en los que no se concluyó tratado alguno entre España y Marruecos. Uno fue en 1977, por existir problemas con la ratificación del acuerdo de pesca, que se resolvieron en 1979, con la visita del Rey Juan Carlos I a Marruecos. El otro fue en 1986, y pudo deberse a factores vinculados a la integración de España en la Comunidad Europea, que aconsejaban esperar un poco para ver cómo podría afectar este ingreso a las relaciones entre ambos países (Torrejón, 2006, 14-15). Tampoco hay que olvidar que en 1986 habían comenzado los conflictos en la ciudad de Melilla a raíz de la aplicación de la ley de Extranjería de 1985, y las situaciones delicadas vividas en la ciudad. De nuevo, el conflicto local en Melilla tenía consecuencias a nivel bilateral e internacional, y así lo reflejó la prensa.

A principios de 1987 el ministro del Interior, José Barrionuevo, iniciaba una visita oficial a Marruecos, donde iba a firmar dos acuerdos de cooperación bilateral, sobre persecución del tráfico de drogas y protección civil. Advirtió que era muy probable que el Gobierno español se viera obligado por la CEE a exigir visados para el acceso a Ceuta y Melilla de ciudadanos no comunitarios, lo que afectaría a la población marroquí cercana. También se iba a tratar la aceptación marroquí de la nueva documentación ofrecida por el Gobierno español a los musulmanes residentes en Ceuta y Melilla, en sustitución de la tarjeta de estadística vigente (ABC, 1987, 21 de enero).

Apenas un mes más tarde se publicó que los servicios de inteligencia españoles investigaban a compañías pesqueras hispano-libias en Canarias, y que además se había detectado la presencia de espías libios, de Siria, Marruecos, Argelia e incluso de potencias occidentales en Melilla (Miguez, Delgado, 1987, 14 de febrero). Una semana después, Javier Solana, ministro de Cultura y portavoz del Gobierno, negó que la CIA u otro organismo dependiente del gobierno norteamericano estuvieran detrás de los incidentes en Ceuta y Melilla. Justificaba sus afirmaciones en el sentido de que Estados Unidos era un aliado de España, entre otras cosas, por la existencia de bases de uso conjunto (ABC, 1987, 21 de febrero).

\subsection{LIBIA}

Tras la firma el 19 de marzo de 1983 de un Tratado de Fraternidad y Concordia entre Túnez y Argelia, Mauritania se adhirió al mismo en diciembre; mientras que Libia, deseosa de formar parte de ese tratado, intentó su inclusión en el mismo, pero se vio frenada por los problemas fronterizos que Argelia urgía a Gaddafi que solventara. La negativa de este a la petición argelina provocó su acercamiento al Marruecos de Hassán II, que mantenía unas relaciones tirantes con Argelia debido al ya citado 
tema de la delimitación de las fronteras y el contencioso del Sáhara Occidental (García Hernando, 2014, 79).

En junio de 1983 Gaddafi visitó a Hassán II, y Marruecos y Libia firmaron el 13 de agosto de 1984 el Tratado de Unión Árabe-Africana en la ciudad marroquí de Oujda $^{5}$. A pesar del Tratado, el aislamiento marroquí en África por el tema del Sáhara Occidental se agravó, y más aún si cabe con esta unión, al despertar la desconfianza de muchos líderes moderados africanos. En los Estados Unidos tal unión no fue bien vista, ya que este último vendía armas a Marruecos y afectaba directamente tanto al flanco sur de la OTAN como a sus comunicaciones por mar y aire, en una zona sensible del Mediterráneo: el norte de África. Si el acuerdo fructificaba sería peligroso para el equilibrio en la zona y afectaría a los intereses occidentales en la región, sobre todo a las facilidades marroquíes de acceso a sus bases (García Hernando, 2014, 80-81).

Libia reducía su aislamiento diplomático y se acercaba al bloque africano occidental. Marruecos, por su parte, contrarrestaba así el Tratado de Fraternidad y Concordia firmado por Argelia, Túnez y Mauritania en 1983, y mostraba al mundo su deseo de independizarse de Estados Unidos, a la vez que intentaba neutralizar a Libia y evitar que siguiera apoyando al Frente Polisario (Lemus, 2005, 307). En el preámbulo del Tratado se destacaba su finalidad, que era ponerse de acuerdo ante los peligros a que se veía sometida la nación árabe, el mundo islámico en general y Palestina en particular. Para Gaddafi, esta era una de las líneas fundamentales y a la que debían subordinarse las demás. Incluso, insistió en que el Frente Polisario uniera sus fuerzas con el Reino de Marruecos para luchar contra Israel (Marquina, 1985, 125).

Gaddafi había acudido a Palma de Mallorca el 19 de diciembre de 1984. El presidente Felipe González se reunió con él para tratar, fundamentalmente, de asuntos comerciales, relacionados sobre todo con el déficit de la balanza de pagos española, en sus relaciones bilaterales con Libia, por los productos energéticos. Ya entonces afirmó que Melilla y Ceuta debían ser árabes, lo que obligó al ministro español de Asuntos Exteriores, Fernando Morán, a convocar al embajador libio para pedirle explicaciones (Miguez, 1984, 20 de diciembre).

El coronel libio intervino varias veces en la marcha de las relaciones hispanomarroquíes. En julio de 1985 la recién creada Unión Libio-Marroquí, en su primera asamblea, reivindicó el carácter árabe de las dos ciudades norteafricanas, y exhortaba a las demás potencias árabes a que las liberaran (Gil, 1985, 13 de julio). El 5 de noviembre, a través de la agencia de prensa oficial libia, Jana, aseguró que Melilla era

${ }^{5}$ El Pais, en su editorial del 2 de septiembre de 1984, hace un interesante análisis de las causas de este Tratado y de las consecuencias que podría tener para España. EL PAÍS.com (1984, 2 de septiembre). 
una ciudad marroqui bajo ocupación española, y que veinte mil ciudadanos árabes marroquíes se encontraban amenazados de expulsión de la misma. Esto se relacionaba con los sucesos de los días previos en Melilla, en relación a la aplicación de la ley de Extranjería a musulmanes residentes en Melilla ( $A B C, 1985,5$ de noviembre).

En mayo de 1987, a partir del encuentro de Hassán II con el primer ministro israelí, Shimon Peres, en verano de 1986, Gaddafi atacó verbalmente al monarca alauí, por lo que este rompió el Tratado de Oujda. El encuentro de Hassan II con el dirigente israelí había supuesto un grave quebrantamiento del Tratado, según Gaddafi (El País, 1986, 30 de agosto). Además, Estados Unidos, socio de Marruecos en aspectos militares, había bombardeado ciudades libias en abril de 1986, con lo que Marruecos se vio forzado a romper con Libia. Desde entonces, Gaddafi intentó arrebatar a Hassán II una reivindicación nacional, como era la de Ceuta y Melilla, y convertirla en un arma arrojadiza contra la estabilidad del régimen (Miguez, 1987, 23 de mayo).

\subsection{INTERAFRICANA SOCIALISTA}

Con la adopción de una carta del socialismo africano en la que se definía a este último como la única vía de desarrollo y de libertad para los países de Africa, opuesta a una visión marxista del continente negro, se constituyó el 28 de febrero de 1981 en Túnez la Internacional Socialista Africana, a iniciativa del ex presidente de Senegal, Senghor y el jefe del Estado tunecino, Burguiba. Once partidos socialistas africanos de tendencia moderada, representando a nueve países (Gambia, Ghana, isla Mauricio, Marruecos, Senegal, Somalia, Sudán, Túnez y Yibuti) fueron los miembros fundadores de la nueva organización, encaminada a limitar la influencia de los países africanos progresistas alguno de los cuales, como Argelia, había delegado una representación, a título de observadora. La organización, calcada en ciertos aspectos de la Internacional Socialista Europea y con sede oficial en Túnez, se declaraba partidaria del socialismo democrático y rechazaba las acusaciones formuladas por el ala progresista, a la que consideraran como agentes de la división y defensores del neocolonialismo (Ostos, 1981, 11 de marzo).

En abril de 1986 la Interafricana Socialista ${ }^{6}$ encargó a Senghor, presidente de la misma, iniciar contactos con el presidente del Gobierno español para tratar sobre Ceuta y Melilla ( $A B C, 1986,10$ de abril). Era el tercer congreso africano, celebrado en Rabat los días 6 al 9 de abril, y participaron partidos socialistas de Marruecos,

${ }^{6}$ Los detalles de la gestación de la Internacional Socialista Africana, que finalmente se constituiría a finales de febrero de 1981, se encuentran en OSTOS, M. (1980, 11 de diciembre). 
Túnez, Senegal, Comores, Mauricio, Gambia, Yibuti y Egipto (El País, 1986, 11 de abril). Ya finalizando el año, la situación de Ceuta y Melilla había sido incluida de nuevo en el orden del día del cuarto congreso, iniciado el 1 de diciembre en el Cairo, a instancias de Marruecos (Orgambides, 1986, 3 de diciembre). Y en junio del año siguiente, reunida en Túnez, pidió una vez más a España, al que consideraba un país amigo, que solucionara el problema de las dos ciudades por la vía pacífica y a través de negociaciones con Marruecos, al considerar que la situación que se estaba dando allí era colonial (Orgambides, 1987, 16 de junio).

\subsection{UNIÓN SOVIÉTICA}

La neutralidad de la Unión Soviética en el conflicto del Sáhara Occidental permitió en 1978 la firma de un contrato con Marruecos por el que se ampliaban las bases de las relaciones económicas bilaterales. Moscú se aseguraba así el suministro de fosfatos y nuevos caladeros para su flota pesquera (Fernández, 2013, 93). El Magreb se encontraba en el área de influencia occidental, y la URSS no esperaba penetrar en la zona buscando la oportunidad de una segunda Cuba, aunque esto no quiere decir que no tuviera expectativas en la zona. En todo caso, el objetivo era neutralizar en lo posible la influencia occidental, pero no reemplazarla (Feliú, 2000, 34).

Hubo una fase de tirantez en 1981, coincidiendo con un relativo acercamiento entre Rabat y Washington, al inicio del mandato de Ronald Reagan: se apresaron cuatro pesqueros soviéticos en aguas del Sáhara, y se acusaba de manera indirecta a la Unión Soviética de proporcionar armas sofisticadas al Frente Polisario, a través de Argelia o de Libia, aunque la intervención directa soviética en el conflicto nunca hubiera sido señalada (Del Pino, 1981, 14 de febrero). Sin embargo, ni la retórica anticomunista de Hassán II ni el acercamiento a Estados Unidos coartarían el desarrollo de estas relaciones, reactivadas tras llegar al poder Mijail Gorbachov en 1985 y el inicio de las reformas aperturistas (Fernández, 2013, 93). El Rey marroquí ya había insinuado que si España recuperaba Gibraltar, la Unión Soviética, que no era miembro de la OTAN, no aceptaría que un país de esta Alianza controlara las dos orillas del Estrecho $(A B C, 1985,9$ de febrero).

En abril de 1986, el embajador soviético en Marruecos, Malik Sabiruitch, hacía unas declaraciones en las que apoyaba la búsqueda de Marruecos de una solución pacífica al problema de Ceuta y Melilla (La Vanguardia, 1986, 5 de abril). En 1987, el Kremlin seguía con interés la situación conflictiva en Melilla, y estaba estudiando 
el cambio en las reivindicaciones marroquíes, el desvincular la situación de Ceuta y Melilla con la de Gibraltar. En Gibraltar, por ejemplo, no había aparecido ningún grupo pro-español (Miguez, 1987, 7 de febrero).

Este apoyo explícito a las reivindicaciones marroquíes se explica por el hecho de que las relaciones entre Marruecos y la URSS eran robustas, caracterizadas por el pragmatismo, que hizo que estas fueran eminentemente comerciales. Marruecos era el principal cliente económico de la URSS en África, y la URSS nunca intentó captar a Marruecos hacia la órbita socialista, pero sí contrarrestar la importante influencia occidental (Feliú, 2000, 38). Por otro lado, hacía menos de un año que España había celebrado un referéndum sobre su permanencia en la OTAN, justo después de su ingreso en la CEE, y el resultado había sido positivo, con lo que, a pesar de que las relaciones hispano-soviéticas distaran de ser malas, España había afianzado definitivamente su alineación con el bloque occidental.

\subsection{ESTADOS UNIDOS}

Marruecos desarrolló lazos importantes con EEUU en el ámbito político y militar, entre otros motivos porque quería lograr un apoyo para sus tesis sobre el Sáhara. En un momento de frialdad en las relaciones con Francia, tras la llegada al poder de los socialistas en el país galo en 1981, Marruecos optó, en su tradicional estrategia del balancín, por el acercamiento a EEUU y a España. Con los primeros, se concedieron facilidades de tránsito a sus Fuerzas Armadas, como el Acuerdo de utilización de bases aéreas marroquíes de mayo de 1982, con la contrapartida de una ayuda militar triplicada (Lemus, 2005, 300).

Esto se hizo a través de la inclusión en el dispositivo de Fuerzas de Despliegue Rápido (FDR). Este plan fue concebido pensando en el problema del abastecimiento de crudo a Europa y en la situación de incertidumbre de las bases militares en la región. Las FDR se integraron en una vasta red de alianzas que otorgaba facilidades de tránsito a EE.UU en una serie de puntos a lo largo del eje Marruecos-Oriente Medio-Océano Indico. Las Fuerzas se estacionaron en América del Norte y las facilidades de tránsito las aportaron Marruecos, Túnez, Egipto, Somalia, Yibuti, Omán y Arabia Saudí. Las bases de Marruecos servirían para otorgar más flexibilidad al sistema y como reserva en el caso de que Portugal y España dejasen de cooperar con EEUU (Feliú, 2000, 36).

Sin embargo, Marruecos quería conservar cierto margen de maniobra frente a los norteamericanos, como muestra el Tratado de Oujda con Libia. En este caso, Estados 
Unidos adoptó una posición pragmática: de presión discreta para romper la unión magrebí sin cuestionar la alianza con Marruecos, y de espera mientras se observaba la evolución de los acontecimientos. La firma del Tratado coincidió con la época de máxima tensión entre Libia y Estados Unidos. Cuando en abril de 1986 se produjo un ataque norteamericano contra el palacio del coronel Gaddafi, los dirigentes marroquíes se vieron obligados a abandonar esta alianza polémica (Feliú, 2000, 37).

El 6 de diciembre de 1986 el secretario de Defensa norteamericano, Caspar Weinberger, fingió en Rabat el desconocer la existencia de Ceuta y Melilla en el curso de una conferencia de prensa celebrada con motivo de su visita a Marruecos (Orgambides, 1986, 7 de diciembre). Marruecos en ese momento trataba de obtener apoyo militar para contrarrestar la introducción de armamento muy sofisticado por parte del Polisario en la guerra del Sáhara (Lemus, 2005, 142). Pero, por otra parte, en España hacía pocos meses que se había celebrado el referéndum por el que España había decidido permanecer en la OTAN, a pesar de que, al llegar al poder, los socialistas habían defendido una política de tendencia antiamericana. Fue la visita del canciller alemán Helmut Khol a España en abril de 1984 y su posición ante la importancia de la pertenencia de España a la estructura occidental las que hicieron cambiar de opinión a Felipe González (Crespo, 2012, 76). Esta apuesta española por su permanencia en la OTAN le hizo ganarse la confianza de Washington.

En febrero de 1987 Estados Unidos y Marruecos firmaron un acuerdo por el cual este último ofrecía su base aérea de Ben Guerir para ser usada por el transbordador espacial de la NASA en caso de aterrizaje de emergencia (El País, 1987, 5 de febrero). En marzo el embajador de Estados Unidos en la ONU, Vernon Walters, afirmaba que el problema de las dos ciudades norteafricanas debía ser abordado por dos países amigos, España y Marruecos, y que Estados Unidos no debía protagonizar ninguna injerencia (El País, 1987, 11 de marzo). Un mes después, varias capitales europeas mostraban sus reservas ante el contencioso entre Madrid y Washington sobre la reducción de la presencia militar norteamericana en territorio español, percibido como malestar diplomático, y se insinuaba que la agitación en Ceuta y Melilla podía ser el motivo de los desencuentros hispano-estadounidenses (Quiñonero, 1987, 6 de abril). A pesar del sí a la OTAN de los españoles, los aliados, europeos y estadounidenses, eran renuentes a permitir una OTAN a la carta, sin bases o armas nucleares, que era lo que buscaba el Gobierno socialista (Centenera, 2007, 286). 


\subsection{FRANCIA}

Así como bajo las presidencias de Pompidou (1969-1974) y Giscard d'Estaing (1974-1981) la sintonía entre Francia y Marruecos debida en gran parte al firme respaldo de Francia a las posiciones marroquíes sobre el conflicto del Sáhara, con Mitterrand (1981-1995) se produjo una crisis de confianza, ya que el presidente francés intensificó sus relaciones con Argelia y estableció contactos directos con el Polisario. También se hallaba comprometido a través de su partido con la oposición marroquí y sus denuncias de represión y violaciones de los derechos humanos. Aunque finalmente prevaleció el realismo y, a partir de 1983, Francia bajó el tono de las críticas en materia de derechos humanos y optó por una posición de neutralidad activa, claramente favorable a Marruecos en el conflicto del Sáhara. Es más, Francia se convirtió en el principal valedor de los intereses comerciales marroquíes en el momento de la entrada de España y Portugal en la CEE (Lemus, 2005, 298-299).

El país galo debía mantener la equidistancia porque, por una parte, las relaciones con España pasaban por un momento muy favorable: los intercambios comerciales entre ambos países aumentaron mucho a partir de 1986, la cooperación en materia antiterrorista era intensa y desde 1983 se habían institucionalizado los encuentros ministeriales francoespañoles. Servían para resolver problemas bilaterales y crear un ambiente favorable a la distensión entre ambos países. Para Fernando Morán, entonces ministro de Asuntos Exteriores, la decisión de crear estos seminarios fue importante para el desbloqueo de la posición francesa sobre el tema de la entrada de España en la CEE. Además, las cumbres a nivel de jefes de Estado y Gobierno se institucionalizaron a partir de marzo 1987 (Trouvé, 2019, 128-129).

Pero, por otra parte, Francia seguía manteniendo una relación muy estrecha con su antigua colonia. Hassan II, según Pierre Vermeren, no esperaba que en 1981 el socialista Mitterrand llegara al Elíseo, pero este siguió el curso habitual de las cosas: Marruecos era el Estado que recibía más ayuda de Francia en el mundo, en todos los sentidos: contribuía a su estabilidad tanto exterior como interior, a cambio de que las élites francesas conservaran unos privilegios sobre todo económicos, heredados de su pasado de potencia colonial en Marruecos (Ruiz; Vermeren, 2015, 337-338).

Esta necesidad por parte de Francia de guardar un equilibrio entre Marruecos y España se puso de manifiesto en la cumbre hispano-francesa que se celebraría en Madrid los días 11 y 12 de marzo, en la que el país galo iba a manifestar su preocupación por las relaciones entre Marruecos y España, dos buenos aliados de París, a causa de Ceuta y Melilla. Para Francia, ese era un conflicto potencialmente peligroso, ya que los puntos de vista de España y Marruecos eran casi incompatibles (Bassets, 
1987, 24 de febrero) y, además, Hassán II sufría grandes presiones de los partidos políticos y de la opinión pública marroquí (Queirolo, 1987, 8 de marzo). Como se había anunciado, el presidente francés, François Mitterrand, sí habló de las dos ciudades, declarando que tanto González como él eran profundamente europeístas pero que, por otra parte, coincidían en la necesidad de establecer una política común con los países ribereños del Mediterráneo, y ahí España tenía algo que decir sobre Ceuta y Melilla (Queirolo, 1987, 12 de marzo).

Un mes más tarde el Gobierno español no creía que Mitterrand, de visita oficial en Marruecos, hablara sobre Ceuta y Melilla con el Rey Hassán II, entre otras cosas porque ni España ni Marruecos deseaban internacionalizar el conflicto $(A B C, 1987$, 23 de abril), y porque suponía un problema para París, puesto que las relaciones con Madrid eran excelentes, pero tampoco podrían oponerse a la autodeterminación de las dos ciudades (Orgambides, 1987, 23 de abril). La Vanguardia aseguró por una parte que el tema de Ceuta y Melilla no se había tratado (Foix, 1987, 24 de abril); en cambio, El País afirmó que Mitterrand sí expresó en Marrakech su deseo de que España y Marruecos llegaran a un arreglo amistoso sobre las dos ciudades, ya que era un problema que afectaba a la soberanía de España y Marruecos y que escapaba de la competencia de Francia (Orgambides, 1987, 25 de abril).

\subsection{OTROS ACTORES}

Hubo más ocasiones en las que las dos ciudades norteafricanas aparecieron en prensa en relación con algún otro actor internacional, en el periodo estudiado, esto es, durante el conflicto surgido en Melilla a partir de la aplicación de la ley de Extranjería. En enero de 1985, un proyecto de resolución para el Parlamento Europeo calificaba a Ceuta y Melilla como colonias españolas, lo que planteaba un problema a la hora de que España ingresara en la Comunidad Económica Europea, puesto que los residentes de estas colonias sí eran reconocidos como ciudadanos españoles con derecho a voto, mientras que los residentes de la colonia británica de Gibraltar no tenían derecho al sufragio (Ortega, 1985, 15 de enero). Un día después, España tuvo que convencer a dos eurodiputados británicos para que introdujeran una enmienda que suprimiera la palabra colonias españolas al referirse a las dos ciudades norteafricanas (Ortega, 1985, 16 de enero).

Otro tema que inquietaba entonces era el hecho de que la OTAN no protegería a Melilla y Ceuta en caso de ataque militar por parte de un país ajeno a la organización. Según declaraciones del secretario de Estado norteamericano adjunto para 
Europa, Richard Burt, el tratado no protegía a los territorios españoles del norte de África; no obstante, sí aclaraba que el ataque a uno de sus miembros era un ataque a todos $(A B C, 1985,18$ de abril).

A finales de año, La Vanguardia entrevistaba a dos dirigentes históricos de la revolución argelina, Ben Bella y Ait Ahmed. Se les preguntó por Ceuta y Melilla y la aplicación de la ley de Extranjería. Ben Bella respondió que Ceuta y Melilla eran marroquíes y que había que evitar situaciones irrevocables para ambas partes. Ait Ahmed respondería que la última palabra la tenía el pueblo marroquí. Ambos, de trayectoria anticolonialista, querían lanzar un manifiesto para la movilización de su pueblo contra el presidente argelino, Chadli Bendjedid, al que acusaban de tirano, y también crear una confederación de países magrebíes: Marruecos, Libia, Túnez, Mauritania y Argelia (Ramos, 1985, 18 de diciembre).

A principios de abril de 1987 la República Federal Alemana (RFA) se negó a jugar un partido entre las selecciones sub-16 de España y la RFA en Melilla, alegando que Melilla no pertenecía al continente europeo. El portavoz de la sección de juveniles de la Federación de fútbol alemana declaró que no querían jugar en el $\mathrm{Ma}$ rruecos español que estaba fuera del continente europeo, en un enclave que estaba en el norte de África, de la misma manera que no jugarían en las islas Malvinas si los británicos insistieran en hacerlo. Esta noticia causó mucho revuelo entre políticos y deportistas melillenses, a pesar de que la Federación de Fútbol alemana aclarara que no existía connotación política alguna, y calificara lo sucedido como una tormenta en un vaso de agua (El País, 1987, 2 de abril).

Este suceso podría haberse quedado en anécdota si no hubiera sido porque intervinieron en el cruce de argumentos y réplicas el Consejo Superior de Deportes de España, el Ministerio de Asuntos Exteriores español y su homólogo alemán (que afirmó que la postura oficial era que Ceuta y Melilla eran territorio español y que los problemas entre España y Marruecos eran estrictamente bilaterales), el Ministro de Cultura español, la Federación Española de Fútbol, la Unión de Federaciones Europeas de Fútbol (UEFA), la Federación Internacional de Fútbol (FIFA), la prensa alemana y el delegado del Gobierno en Melilla. Por la parte alemana, había un profundo desconocimiento de la ubicación y la realidad política de Melilla, y por la parte española se defendió, sin éxito, que otros partidos se habían jugado fuera del estricto territorio europeo, como en la isla de Madeira, o que la selección sub-16 israelí jugó en territorio europeo.

A mediados de julio, el Frente Polisario manifestó su voluntad de normalizar sus relaciones con el Gobierno español y con la oposición y defendió que, antes de 
pedir la descolonización de las ciudades de Ceuta y Melilla, Marruecos debía descolonizar primero el Sáhara Occidental, que estaba ocupado en contra de las resoluciones de la Organización para la Unidad Africana y Naciones Unidas, favorables a la autodeterminación, y que el Gobierno marroquí ignoraba sistemáticamente (Miguez, 1987, 13 de julio, a).

Aunque en ese momento las relaciones entre España y el Frente Polisario estaban bajo mínimos tras el ataque a la patrullera Tagomago y al pesquero Junquito por patrulleras del Frente, había habido un acercamiento entre miembros del PSOE y del Frente Polisario. Además, España había votado siempre a favor de las tesis argelinas, es decir, saharauis, ante las Naciones Unidas, lo que había provocado la ira del Rey Hassán II y el aplazamiento, en dos ocasiones, de sus visitas oficiales a España. El Frente Polisario le negaba toda autoridad moral y política a Hassán II para exigir la entrega de Ceuta y Melilla mientras mantuviera su ocupación militar en el Sáhara (Miguez, 1987, 13 de julio, b).

\section{CONCLUSIONES}

La ley de Extranjería de 1985 daba un trato preferencial a aquellas personas originarias de territorios sobre los que España hubiera ejercido su protectorado a la hora de solicitar la nacionalidad española. Ceuta y Melilla, por tanto, quedaban fuera de estos territorios, y muchos residentes de ambas ciudades, de origen marroquí, se veían abocados a la expulsión a Marruecos. Esta complicada situación generó cientos de artículos y de opiniones en la prensa escrita.

Los movimientos de protesta en contra de la aplicación de la ley de Extranjería en Melilla y Ceuta cambiaron para siempre la fisonomía humana de ambas ciudades. Aomar Mohamedi Duddú, fue un líder necesario para movilizar la masa de población de origen marroquí residente en Melilla y Ceuta la cual, en su mayoría, vivía por entonces en condiciones de pobreza y marginalidad. Denunció el racismo de la mayoría de la población melillense de ese momento, y consiguió ser escuchado en Madrid, aunque la ambigüedad que mostró cuando se relacionó con el Rey Hassán II y con la cúpula de su Gobierno le hizo perder credibilidad, hasta que su situación en Melilla se hizo insostenible y acabó exiliándose en Marruecos.

El conflicto originado en Melilla trascendió su origen local y alcanzó una dimensión internacional, como ha quedado demostrado tras la revisión de los artículos de prensa recogidos en este análisis. Se ha confirmado la intensa actividad diplomática que desplegó Marruecos en estos años, tanto el propio Rey Hassán II como su 
Gobierno, e incluso partidos de la oposición. El monarca alauí, a tenor de lo leído, usó el conflicto originado en Melilla para reavivar la reivindicación de las dos ciudades norteafricanas en un momento delicado, puesto que España acababa de ingresar en la CEE y Marruecos se disponía a solicitar su ingreso.

El Gobierno marroquí, así como los partidos políticos de la oposición, tanto de izquierdas como el nacionalista Istiqlal, organizaron una intensa y por momentos agresiva campaña de reivindicación de Ceuta y Melilla, exigiendo a España que les fueran devueltas. Sin embargo, la inmensa mayoría de musulmanes residentes en Ceuta y Melilla que, por otra parte, tenían la nacionalidad marroquí, querían obtener la nacionalidad española. Los partidos políticos marroquíes en la oposición usaron el conflicto de Melilla para mostrar sus discrepancias con la corona alauí. El mismo Hassán II en algún momento desautorizó las amenazas del Istiqlal acerca de realizar una nueva Marcha Verde sobre Melilla.

De lo recogido en la prensa, se deduce que el Gobierno español aparentemente no dio demasiada importancia a las reclamaciones territoriales de Marruecos. No respondió a cada una de las manifestaciones del Rey o de políticos marroquíes sobre Ceuta y Melilla. Sin embargo, sí tuvo que buscar una solución a las reivindicaciones planteadas por los marroquíes residentes en ambas ciudades, sobre todo en Melilla. Había temor a que la violencia en las calles fuera en aumento. También se alzaron voces críticas contra la gestión gubernamental al inicio del conflicto que la prensa recogió, principalmente en El País. Por momentos, daba la impresión de que en Madrid se actuaba con cierta improvisación en la aplicación de medidas para corregir la situación de los residentes en Ceuta y Melilla de origen marroquí.

En la escena internacional, hubo países que apoyaron decididamente las reivindicaciones de Marruecos. El coronel Gaddafi, quien al principio del conflicto, estaba vinculado al monarca alauí a través del Tratado de Oujda, afirmó que Ceuta y Melilla eran marroquíes en varias ocasiones, hasta que la ruptura de dicho tratado, a raíz del encuentro de Hassán II con el primer ministro israelí, Shimon Peres, le hizo usar el tema de las dos ciudades como un arma arrojadiza contra la estabilidad del régimen marroquí.

Con respecto a la Unión Soviética, su apoyo a las tesis marroquíes tenía un origen más estratégico y económico. Por una parte, se mostró neutral en el conflicto del Sáhara Occidental. Así, se aseguraba suministros de fosfatos y caladeros para su flota pesquera. Además, según el propio Hassán II, no aceptaría que un miembro de la OTAN controlara las dos orillas del estrecho de Gibraltar en el caso de que España recuperara la colonia británica. En el caso de la Interafricana Socialista, hubo una 
cuestión ideológica de base; consideraban que la situación en Ceuta y Melilla era colonial. Por otra parte, tanto Estados Unidos como Francia consideraron que era prudente mantener la equidistancia y no caer en la injerencia en unos asuntos que ambas potencias entendían que eran de carácter puramente bilateral. La red de intereses que tanto Estados Unidos como Francia tenían tejida en España y Marruecos les impedía tomar partido por uno de los dos países.

\section{REFERENCIAS BIBLIOGRÁFICAS}

\subsection{BIBLIOGRAFRÍA}

BALlesteros, A. (1989): Estudio diplomático sobre Ceuta y Melilla, Córdoba (Argentina) Editorial Lerner.

BELMONTE, F. (2010): La ley de Extranjería de 1985 y la transformación del espacio público en la ciudad de Melilla, Melilla, Ediciones Instituto de las Culturas de Melilla.

BOUNDI BOUNDI, M. (2010): “Los partidos y la emancipación política en Marruecos”, En Martín, A. y Gallego, S. (coord.), VIII Premio Ensayo Breve de la Asociación Castellano Manchega de Sociología "Fermín Caballero", Madrid, Asociación castellano-manchega de Sociología, pp. 41-66.

CARABAZA, E.; DE SANTOS, M. (1992): Melilla y Ceuta. Las últimas colonias, Madrid, Editorial Talasa.

CENTENERA, J. (2007): Relaciones hispano-soviéticas de 1976 a 1986 (Tesis doctoral, UNED).

CRESPO PALOMARES, C. (2012): La estrategia atlantista en la Política Exterior española (1996-2004) (Tesis doctoral, Universidad de Alcalá de Henares).

DE LA FUENTE CASAMAR, M. (1989): "Las relaciones entre Marruecos y la Comunidad Europea. Proceso global de una política de acercamiento", Afers Internacionals (17), pp. 69-96.

FELIÚ, L. (2000): "La situación del Magreb en la escena internacional actual", Cuadernos de estrategia (106), pp. 19-68.

FERNÁNDEZ MOLINA, I. (2013): La politica exterior de Marruecos en el reinado de Mohamed VI (1999- 2008): Actores, discursos y proyecciones internas (Tesis doctoral, Universidad Complutense).

FLORES, I. (ED.). (1995): Diez años de Historia de Melilla a través de Melilla Hoy, Melilla, Editorial Prensa de Melilla, S. A.

GARCÍA HERNANDO, J. L. (2014): La proyección mediterránea de la Alianza Atlántica: España y Marruecos, una encrucijada de intereses en la frontera sur de la OTAN y de la UE (de 1981 a nuestros días), (Tesis doctoral, Universidad de Valladolid). 
HERNANDO DE LARRAMENDI, M. (1995): "La política exterior de Marruecos, dominio reservado de la Monarquía”, En Moyano Estrada, E. y Desrues, T. (Coords.), La realidad política y social del Magreb contemporáneo. Una reflexión desde las dos orillas, Córdoba, Instituto Estudios Sociales Avanzados, pp. 57-74.

JEDIDI, S. (2019): “La imagen de América Latina en el diario marroquí Al-Alam”, https://infomarruecos.ma/la- imagen-de-america-latina-en-el-diario-marroqui-al-alam-primera-parte-autor-hiri-abdelhak/ [Consultado el 30/6/2020].

LEMUS DE LA IGLESIA, U. (2005): Cambio y continuidad en la politica exterior de España hacia Marruecos: de la política de equilibrios a la política global (1982-1996), (Tesis doctoral, Universidad de Santiago de Compostela).

LOUREIRO SOUTO, J.L. (2015): Los conflictos por Ceuta y Melilla: 600 años de controversias, (Tesis doctoral, Instituto Universitario General Gutiérrez Mellado, UNED).

MARQUINA, A. (1985): "El tratado libio-marroquí, repercusiones e incidencia en la política exterior española”, Revista de Estudios Internacionales (6), pp. 125-136.

MORATA, J. (2020): https://jesusmorata.es/videos-y-postales/entrevista-a-jesus-morata/ Consultado el 11/9/2021.

ORAA, J.; RUIZ, E.; GIL, M. T. (1997): “El extranjero ante el Derecho”, En: El extranjero en la cultura europea de nuestros días, Bilbao, Universidad de Deusto, pp. 314-336.

PARK, T.; BOUM, A. (2005): Historical Dictionary of Morocco, Toronto, The Scarecrow Press.

PLANET, A. I. (1998): Melilla y Ceuta. Espacios-frontera Hispano-Marroquies, Melilla, Ciudad Autónoma de Melilla.

RUIZ, C.; VERMEREN, P. (2015): "Francia-Marruecos: Te quiero... yo tampoco", Razón Española, 191, pp. 336-344.

SAINZ DE LA PEÑA, J. A. (1997): "La política de inmigración en España”, En: Marquina, A. (Ed.) Flujos migratorios norteafricanos hacia la Unión Europea. Asociación y diplomacia preventiva, Madrid, Ediciones Mundo árabe e Islam, pp. 123-310.

SZMOLKA, I. (2005): El conflicto del Perejil, Ceuta, Archivo Central de Ceuta.

THIEUX, L. (2007): "Las relaciones hispano-argelinas desde el final de los años ochenta: el laborioso camino hacia un verdadero partenariado estratégico", Anales de Historia Contemporánea (23), pp. 241-256.

TROUVÉ, M. (2019): “Francia-España: una relación privilegiada en el contexto del fin de la Guerra Fría (1986-2001)”, Comillas Journal of International Relations (2019), pp. 125-137.

\subsection{HEMEROGRAFÍA}

$A B C$

(1985, 9 de febrero): "Hassan reclamará Ceuta y Melilla si España recupera Gibraltar”, p. 15. (1985, 18 de abril): “La OTAN no se compromete a proteger a Ceuta y Melilla”, p. 3. (1985, 5 de noviembre): "El dictador Gaddafi agita a los árabes contra España”, p. 3. 
(1985, 7 de diciembre): "Hassán quiere negociar el estatuto de los marroquíes en España”, p. 19. (1986, 26 de enero): "Nueva campaña de la prensa marroquí sobre Ceuta y Melilla", p. 22. (1986, 7 de febrero): “Convocatoria de concentración marroquí cerca de Melilla”, p. 30. (1986, 26 de marzo): "Hassán II habla de paciencia y diálogo sobre Ceuta y Melilla”, p. 17. (1986, 28 de marzo): "Muchos musulmanes de Ceuta y Melilla no quieren la nacionalidad española", p. 16.

(1986, 10 de abril): "Encargan a Senghor negociar sobre Ceuta y Melilla", p. 25.

(1987, 21 de enero): "Barrionuevo intenta mejorar en Rabat las relaciones hispano-marroquíes", p. 21.

(1987, 24 de enero): “Afrenta a Hassán II”, p. 20.

(1987, 21 de febrero). "Solana: la CIA no está detrás de los disturbios de Melilla", p. 18. (1987, 13 de abril). "Hassán II se prohíbe marchar sobre Ceuta o Melilla”, p. 19

(1987, 23 de abril). "El Gobierno duda que Mitterrand hable sobre Ceuta y Melilla en Marruecos", p. 35.

(1987, 13 de julio). "Hassán II une el futuro de Gibraltar a Ceuta y Melilla”, p. 3.

Bassets, L.

(1987, 24 de febrero): "Francia, preocupada por las relaciones entre Madrid y Rabat", EL PAÍS, http://elpais.com/diario/1987/02/24/espana/541119615_850215.html

Besa, R.

(1987, 1 de abril): "No queremos jugar en el Marruecos español”, EL PAÍS, https://elpais.com/diario/1987/04/01/deportes/544226404_850215.html

Carrascosa, J. L.

(1986, 9 de octubre): "Duddú podría haber mantenido contactos secretos con el Gobierno de Marruecos", $A B C$, p. 23.

Del Pino, D.

(1981, 14 de febrero): "Tirantez en las relaciones de Marruecos con la Unión Soviética”, EL PAÍS, https://elpais.com/diario/1981/02/14/internacional/350953206_850215.html (1985, 10 de enero): "Hassan considera que la solución del problema de Ceuta y Melilla sólo puede ser política”, EL PAÍS, https://elpais.com/diario/1985/01/10/espana/47 4159615_850215.html

Duddú, A. M.

(1985, 11 de mayo): “Legalizar Melilla”. EL PAÍS, http://elpais.com/diario/1985/ 05/11/ espana/484610406_850215.html

\section{El País}

(1984, 2 de septiembre): "La alianza entre Libia y Marruecos", http://elpais.com/diario/1984/09/02/opinion/462924001_850215.html

(1986, 11 de abril). "La Interafricana Socialista apoya a Marruecos sobre Ceuta y Melilla", https://elpais.com/diario/1986/04/11/espana/513554407_850215.html 
(1986, 30 de agosto). Marruecos rompe el tratado de unión con Libia, https://elpais.com/diario/1986/08/30/internacional/525736810_850215.html

(1987, 5 de febrero). “Acuerdo EEUU-Marruecos”, https://elpais.com/diario/1987/02/05 /internacional/539478020_850215.html

(1987, 11 de marzo). "Vernon Walters afirma que Estados Unidos no debe injerirse en el problema de Ceuta y Melilla", http://elpais.com/diario/1987/03/11/espana/542415603_8 50215.html

(1987, 2 de abril). "Para la RFA, "tormenta en un vaso de agua"”, https://elpais.com/di ario/1987/04/02/deportes/544312804_850215.html

Foix, L.

(1987, 24 de abril): "Mitterrand visitó Marruecos dentro de su política conciliatoria con todos los países de la zona", La Vanguardia, p. 8.

Garrigo, A.

(1987, 21 de julio): "La petición de adhesión de Marruecos a la CEE se debatirá en septiembre", La Vanguardia, p. 9.

Gil, V.

(1985, 13 de julio): "Mutismo gubernamental ante las pretensiones libio-marroquíes de anexionar Ceuta y Melilla", $A B C$, p. 19.

Grijelmo, A.

(1987, 5 de febrero). El juez procesa a Dudú por incitar a la subversión, EL PAÍS, https://elpais.com/diario/1987/02/05/espana/539478007_850215.html

La Vanguardia

(1985, 4 de diciembre): "El partido marroquí Istiqlal, contra la ley de Extranjería”, p. 18. (1986, 18 de enero): “Líder marroquí pide «liberar» a Ceuta y Melilla”, p. 15.

(1986, 5 de abril): “Opinión soviética sobre Ceuta y Melilla”, p. 12.

(1987, 2 de febrero): "Madrid consideraría una ofensa la concesión a Duddú de un estatuto de refugiado", p. 13.

(1987, 10 de febrero): "El socialismo marroquí quiere llevar la cuestión Ceuta-Melilla a Estrasburgo", p. 3.

(1987, 15 de febrero): “Aomar Duddú llama a la tranquilidad a la comunidad musulmana de Melilla", p. 15.

(1987, 7 de mayo): "Duddú abandona Melilla para vivir definitivamente en Rabat", p. 3. Miguez, A.

(1984, 20 de diciembre): "La oposición pide una clarificación de la visita de Gaddafi", $A B C$, p. 23.

(1985, 26 de noviembre): “Ahmed Osman critica el trato a marroquíes de Ceuta y Melilla", $A B C$, p. 29.

(1986, 8 de marzo): Según Hassán II, la situación de Ceuta y Melilla «cambiará por la fuerza de la historia», La Vanguardia, p. 3. 
(1987, 23 de enero): Hassán II propone a España hablar sobre Ceuta y Melilla; Ordóñez: «Las dos ciudades seguirán siendo españolas», $A B C$, p. 19.

(1987, 7 de febrero): Próximo giro "copernicano" de Marruecos sobre el contencioso, La Vanguardia, p. 13.

(1987, 23 de mayo): "La sombra de Gaddafi aparece en el problema de Ceuta y Melilla", La Vanguardia, p. 22.

(1987, 13 de julio, a): "El Frente Polisario quiere normalizar en otoño sus relaciones con el Gobierno español; Réplica a las peticiones de Hassán II”, La Vanguardia, p. 9.

(1987, 13 de julio, b): "Réplica a las peticiones de Hassan II", La Vanguardia, p. 9.

Miguez, A., Delgado, F.

(1987, 14 de febrero): "Los Servicios de Inteligencia investigan a las compañías hispanolibias en Canarias", $A B C$, p. 15.

Orgambides, F.

(1985, 7 de diciembre): "El Gobierno garantiza a Hassán II que no habrá expulsiones masivas”, EL PAÍS, http://elpais.com/diario/1985/12/07/espana/502758009_85021 5.html

(1985, 10 de diciembre): “Los nacionalistas marroquíes, decididos a «liberar» Ceuta y Melilla", EL PAÍS,

http://elpais.com/diario/1985/12/10/espana/503017214_850215.html

(1986, 26 de marzo): "Hassan II quiere "diálogo, ponderación y persuasión para solucionar el contencioso de Ceuta y Melilla", EL PAÍS, https://elpais.com/diario/1986/03/26/espana/512175601_850215.html

(1986, 23 de octubre): “Ceuta y Melilla son un peso para España según un dirigente socialista marroquí, EL PAÍS, http://elpais.com/diario/1986/10/23/espana/530406020_850 215.html

(1986, 11 de noviembre): "Satisfacción en Rabat por el giro del conflicto, pese al silencio oficial”, EL PAÍS, http://elpais.com/diario/1986/11/11/espana/532047610_850215.html (1986, 1 de diciembre): "Rabat informará sobre Ceuta y Melilla a los ministros de la CE que visiten Marruecos", EL PAÍS, http://elpais.com/diario/1986/12/01/espana/533775619 _850215.html

(1986, 3 de diciembre): "Los socialistas africanos analizan la situación de Ceuta y Meli1la”, EL PAÍS, http://elpais.com/diario/1986/12/03/espana/533948425_850215.html (1986, 7 de diciembre): "Weinberger finge en Rabat desconocer dónde están Ceuta y Melilla”, EL PAÍS, http:/elpais.com/diario/1986/12/07/espana/534294014_850215.html (1987, 23 de abril). "Mitterrand llega a Marruecos en una coyuntura regional difícil", $E L$ PAÍS, http://elpais.com/diario/1987/04/23/internacional/546127213_850215.html (1987, 25 de abril). "Mitterrand espera un arreglo entre España y Marruecos sobre Ceuta y Melilla”, EL PAÍS, http://elpais.com/diario/1987/04/25/espana/546300006_85021 5.html 
(1987, 16 de junio). "La Interafricana Socialista pide soluciones para Ceuta y Melilla", EL PAÍS, http://elpais.com/diario/1987/06/16/espana/550792818_850215.html

Ortega, A.

(1985, 15 de enero): "Ceuta y Melilla son "colonias" según un proyecto del Parlamento Europeo”, EL PAÍS, https://elpais.com/diario/1985/01/15/espana/474591614_85021 5.html

(1985, 16 de enero): "Eliminada la palabra "colonias" de un texto parlamentario europeo sobre Ceuta y Melilla”, EL PAÍS, https://elpais.com/diario/1985/01/16/espana/474678 010_850215.html

Ostos, M.

(1980, 11 de diciembre): "Intento de creación de una internacional socialista africana", EL PAÍS, https://elpais.com/diario/1980/12/11/internacional/345337214_850215.html (1981, 11 de marzo): “Constituida la Internacional Socialista Africana”, EL PAÍS, https://elpais.com/diario/1981/03/01/internacional/352249209_850215.html

Queirolo, P.

(1987, 8 de marzo): "La situación en Ceuta y Melilla estará presente en la cumbre hispano-francesa", La Vanguardia, p. 23.

(1987, 12 de marzo): "Preocupación en Francia por la facilidad con que son puestos en libertad algunos vascos entregados", La Vanguardia, p. 13.

Quiñonero, J. P.

(1987, 6 de abril): "Preocupación en Europa por la crisis España- USA sobre la reducción de tropas", $A B C$, p. 20.

Ramos, M.

(1985, 18 de diciembre): "Propuesta de creación de una confederación de países magrebíes basada en principios islámicos”, La Vanguardia, p. 4.

Ramírez, S.

(1986, 29 de enero). "Graves incidentes en Melilla al disolver la Policía una manifestación de musulmanes", $A B C$, p. 21.

(1986, 9 de noviembre). "Los musulmanes piden «una Melilla magrebí»”, $A B C$, p. 3.

Sonia RUBIANO SEGOVIA

http://orcid.org/0000-0001-8465-6792

soniarubiano@gmail.com 